Федерации территориальное планирование направлено на определение в его документах назначения территорий исходя из совокупности социальных, экономических, экологических и иных факторов в целях обеспечения устойчивого развития территорий, развития инженерной, транспортной и социальной инфраструктур, обеспечения учета интересов граждан и их объединений, Российской Федерации, субъектов РФ, муниципальных образований.

$$
* * *
$$

1. http://genproc.gov.ru/smi/news/genproc/news-1275006/ Дата обращения 15.01.201

2. Постановление Правительства РФ от 29.05.2008 № 404 (ред. от 28.01.2011) «О Министерстве природных ресурсов и экологии Российской Федерации»

3. Государственный доклад «О состоянии и об охране окружающей среды Российской Федерации в 2015 году». - М.: Минприроды России; НИА-Природа. - 2016. - С. 180.

4. Государственный доклад «О состоянии и об охране окружающей среды Российской Федерации в 2015 году». - М.: Минприроды России; НИА-Природа. - 2016. - С. 181.

\title{
Усманов Р.Ф. \\ Предупреждение и разрешение конфликта интересов в органах внутренних дел Российской Федерации
}

Академия Управления МВД России (Россия, Москва)

doi:10.18411/spc-20-03-2018-08

idsp: 000001:spc-20-03-2018-08

В последние годы в Российской Федерации разработан и реализуется комплекс мер, направленных на разрешение конфликта интересов в системе государственной службы. Данная работа велась и ведется по трем основным направлениям: преодоление личных конфликтов интересов, то есть связанных с персональными интересами агента - должностного лица; преодоление организационных конфликтов интересов, связанных с наличием противоречивых требований к государственным служащим со стороны самого государства как организация; совершенствование организации административного учета как инструмента внутригосударственного и общественного контроля за действиями служащих.

Так, для решения проблем персонального конфликта интересов государством предлагается использовать следующие меры. Во-первых, повышение информационной открытости органов государственной власти. Под информационной открытостью органов государственной власти, включая правоохранительные органы, предлагается понимать относительную доступность в получении информации гражданами (организациями и объединениями) об их деятельности. Подчеркивается, что принятый 9 февраля 2009 г. Федеральный закон РФ от 9 февраля 2009 г. №8-Ф3 «Об обеспечении доступа к информации о деятельности государственных органов и органов местного самоуправления» внесет существенный вклад в расширение информационной открытости органов государственной власти, включая органы внутренних дел. Немаловажным в этой связи представляется и создание механизмов общественного контроля за деятельностью органов государственной власти.

Во-вторых, речь идет о создании системы административных регламентов, используя которые можно будет судить о правомерности действий должностного лица. Без наличия таких регламентов информационная открытость и административный учет будут малоэффективны.

В-третьих, речь идет о сокращении вмешательства государства в экономику и общественную жизнь. 
В-четвертых, о введении процедур обязательного декларирования о конфликте интересов, который возникает у должностного лица при разрешении того или иного дела.

Далее необходимо обратить внимание на проблему организационного конфликта. Основой разрешения организационного конфликта, как в частном, так и в государственном секторе является разведение противоречивых функций по различным должностным лицам, отделам или ведомствам. Принцип недопустимости совмещения бюрократической и государственно-предпринимательской деятельности должно дополнить уже принятое требование недопустимости совмещения нормотворчества и контрольно-надзорной деятельности, контрольно-надзорной деятельности и другой правоприменительной деятельности.

Акцентируется также внимание на административном учете. В данное время он ведется преимущественно в бумажной форме, тогда как все большее количество действий (межведомственная переписка, ведение баз данных и т.д.) ведется в электронной форме. При этом электронная информация в отличие от сохраненной на бумаге имеет справочный статус, не обладает свойством официальной признанности. Эта ситуация искусственно порождает необходимость дублирования электронных технологий бумажными, что создает ненужные издержки. В этой связи необходимо определить требования, обеспечивающие полезность использования учета; возможность независимого аудита, судебной экспертизы, оперативно-розыскных действий и иных форм проверки содержания и функционирования системы учета; требования к защите систем электронного административного учета, к их прозрачности для граждан, доступности; основные принципы выделения бюджетных средств на приведение в соответствие с требованиями действующих систем учета.

В целях минимизации негативных последствий конфликтов интересов в системе государственной службы необходимо последовательно реализовывать организационные и правовые меры по всем трем направлениям.

Совершенствование организационных основ разрешения конфликта интересов сотрудников органов внутренних дел подразумевает, в первую очередь, создание эффективной системы, позволяющей своевременно диагностировать (выявлять) ситуации конфликта интересов в системе органов внутренних дел, устанавливать причины (условия) возникновения конфликта интересов, круг заинтересованных сторон конфликта, а также своевременно влиять на данные условия, т.е. приводить личные интересы сотрудников органов внутренних дел и самой организации к единому основанию на основе апробированных организационно-правовых средств и методов.

Система разрешения конфликта интересов должна действовать на основе следующих принципов: обязательное раскрытие сведений о реальном или потенциальном конфликте интересов или даже видимости такого конфликта; индивидуальное рассмотрение, оценка серьезности рисков для органов внутренних дел каждого конфликта интересов и урегулирование каждого случая конфликта интересов; конфиденциальность процесса раскрытия сведений о конфликте интересов и процесса урегулирования (по желанию сотрудника); соблюдение баланса интересов органов внутренних дел и сотрудника при урегулировании конфликта интересов; защита сотрудника от преследования в связи с конфликтом интересов, который был своевременно раскрыт самим сотрудником.

Закрепленный нормативно механизм разрешения конфликта интересов в органах внутренних дел в основном возлагает обязанности по декларированию конфликта на самих сотрудников. Между тем, учитывая многомерность условий возникновения конфликта интересов в органах внутренних дел, механизм разрешения таких конфликтов может включать в себя следующие варианты и формы: орган (органы) внутренних дел, после проведения проверки и иных необходимых действий, не расценивает как конфликт интересов те ситуации, которые, по мнению 
декларировавшего их сотрудника, создают или могут создать конфликт с интересами органа (органов) внутренних дел;ограничение сотруднику органов внутренних дел доступа к конкретной информации, которая может иметь отношение к частным интересам сотрудника; добровольный отказ сотрудника органов внутренних дел или его отстранение - постоянно или временно - от участия в обсуждении и процессе принятия решений по вопросам, которые находятся или могут оказаться под влиянием конфликта интересов; пересмотр и изменение круга обязанностей и служебных функций сотрудника;временное отстранение сотрудника от должности, если его или ее частные интересы входят в противоречие с должностными обязанностями; перевод сотрудника на должность, предусматривающую выполнение служебных функций, не связанных с конфликтом интересов; увольнение сотрудника из органов внутренних дел по инициативе самого сотрудника; увольнение сотрудника по инициативе органов внутренних дел за дисциплинарные проступки при наличии оснований, предусмотренных применимым правом; передача имущества, составляющего конфликтный частный (личный) интерес, в доверительное управление; отказ сотрудника органов внутренних дел от своего частного (личного) интереса, порождающего конфликт с интересами органов (органа) внутренних дел.

В целях минимизации основных рисков, связанных с реальным или потенциальным конфликтом интересов, органы внутренних дел могут запрещать своим сотрудникам: использовать в личных интересах или интересах третьего лица деловые возможности, о которых сотруднику стало известно в связи с работой в органах внутренних дел или использованием имущества и/или информации органов внутренних дел; участвовать в целях получения прибыли или иной личной выгоды во взаимоотношениях с организациями, с которыми органы внутренних дел в ситуации во взаимоотношения, если такое участие не было сначала одобрено в письменной форме руководством органов внутренних дел в пределах полномочий, делегированных сотруднику самим руководством; передавать третьим лицам внутреннюю информацию органов внутренних дел в отношении в собственных интересах или в интересах третьих лиц; участвовать в любой деятельности вне занятости в органах внутренних дел, которая противоречит требованиям органов внутренних дел к рабочему времени сотрудника, или которая влечет использование к выгоде стороннего работодателя возможностей органов внутренних дел, информации, являющейся собственностью государства (органов внутренних дел), полученных во время работы в системе органов внутренних дел.

Важным элементом системы разрешения конфликта интересов в органах внутренних дел должны стать комиссии по соблюдению требований к служебной дисциплине и урегулированию конфликта интересов. В настоящее время в органах внутренних дел созданы и действуют комиссии по служебной дисциплине и профессиональной этике. Однако в наименовании таких комиссий не закреплен термин «конфликт интересов». Видимо в силу отсутствия Федерального закона «О правоохранительной службе РФ» создание таких комиссий в органах внутренних дел пока не возможно. Между тем, необходимо создать проект положения о таких комиссиях.

В организационном плане к наиболее распространенным средствам разрешения конфликта интересов можно отнести: отстранение от отдельных работ; делегирование полномочий (должностное лицо делегирует другому должностному лицу полномочия на принятие мер или решений в области, где может возникнуть конфликт интересов); отставка; отказ от личных интересов; отказ от подарков и иных выгод; повышение прозрачности и тщательный анализ решений.

В контексте обсуждаемых проблем совершенствования организационных основ разрешения конфликта интересов в деятельности сотрудников органов внутренних дел возможно выделить ряд предложений, направленных на профилактику самих условий 
возникновения конфликта интересов: формирование перечня должностей, в наибольшей степени подверженных риску коррупции, а также примерного перечня коррупционных действий и проявлений в деятельности сотрудников органов внутренних дел; обеспечение доступа физических и юридических лиц к информации о деятельности органов внутренних дел; расширение обратной связи с получателями государственных услуг; внедрение и развитие информационно-коммуникационных технологий в деятельности органов внутренних дел в целях сокращения причин и условий, порождающих конфликт интересов; создание системы внутреннего контроля, основанной на механизме служебных проверок; развитие технических средств контроля за деятельностью сотрудников, замещающих должности, в наибольшей степени подверженных риску коррупции, а также применение технических средств контроля деятельности сотрудников в процессе исполнения государственных функций, связанных с непосредственным взаимодействием с физическими и юридическими лицами.

Таким образом, на основании изложенного, приходим к следующим выводам:

I. Важной особенностью деятельности ОВД является противоречивый конфликтный характер их функционирования в сфере правопорядка.

II. Успехи или неудачи в разрешении острых конфликтных ситуаций в ОВД сказываются на микроклимате:

- в отдельных подразделениях;

- на взаимоотношениях конкретных сотрудников;

- на результатах работы.

III. Необходимо учитывать приведенные классификации и формы в деятельности сотрудников ОВД, направленной на поиск путей разрешения конфликтов в правоохранительной деятельности.

$$
* * *
$$

1. Матвеев Д.Д. Правовое и организационное обеспечение разрешения конфликта интересов в служебной деятельности сотрудников органов внутренних дел/ Автореферат диссертации на соискание ученой степени кандидата юридических наук. Москва. 2009.

2. Лобанов П.А. Региональные аспекты управления конфликтами в органах государственной власти // Этносоциум и межнациональная культура. - М., 2009. № 1.

3. Тонков Е. Е Управление конфликтами в органах внутренних дел: Учебное пособие. - Белгород: ОН и РИО, 2001.

4. Олейник А. Н. Основы конфликтологии. Психологические средства деятельности сотрудников органов внутренних дел в ситуации конфликтов. - М. , 1992.

5. Андреев В.И. Конфликтология. Искусство спора, ведения переговоров, разрешения конфликтов. M., 1995.

\section{Филатова К.С. \\ Классификация межмуниципального сотрудничества в Российской Федерации}

Дальневосточный Федеральный университет (Россия, Владивосток)

doi:10.18411/spc-20-03-2018-09

idsp: 000001:spc-20-03-2018-09

В настоящее время в значительной части муниципальных образований субъектов Российской Федерации не хватает средств для реализации программ социально-экономического развития, направленных на решение вопросов местного значения. В связи с тем, что размер финансовых и иных ресурсов, необходимых для исполнения муниципальными образованиями установленных обязательств, не соответствует уровню их реальных потребностей, а дотации от государства не покрывают всех расходов одним из способов оптимизации механизма решения вопросов местного значения, повышения эффективности деятельности органов 